\title{
Mucinous cystic neoplasms of the liver: a clinicopathological study and comparison with intraductal papillary neoplasms of the bile duct
}

Yoh Zen ${ }^{1, *}$, Federica Pedica ${ }^{2, *}$, Venkata R Patcha ${ }^{1}$, Paola Capelli ${ }^{2}$, Giuseppe Zamboni ${ }^{2,3}$, Andrea Casaril ${ }^{4}$, Alberto Quaglia ${ }^{1}$, Yasuni Nakanuma ${ }^{5}$, Nigel Heaton ${ }^{1}$ and

Bernard Portmann ${ }^{1}$

${ }^{1}$ Institute of Liver Studies, King's College Hospital, London, UK; ${ }^{2}$ Department of Pathology, University of Verona, Verona, Italy; ${ }^{3}$ Department of Pathology, Sacro Cuore Hospital, Negra, Verona, Italy; ${ }^{4}$ Department of General Surgery, Casa di Cura Polispecialistica 'Dott. Pederzoli', Peschiera del Garda, Verona, Italy and ${ }^{5}$ Department of Human Pathology, Kanazawa University, Kanazawa, Japan

\begin{abstract}
Mucinous cystic neoplasm of the liver has been a controversial entity, in particular, regarding differentiation from intraductal papillary neoplasm of the bile duct. In this study, we compared the characteristics of hepatic mucinous cystic neoplasms with ovarian-like stroma $(n=29)$ to those of cyst-forming intraductal papillary neoplasms of the bile duct $(n=12)$. Radiological or macroscopic appearance, histological grade of malignancy, and postoperative clinical course were recorded. Immunohistochemistry for biliary or gastrointestinal markers was performed to characterize cell phenotypes. The patients with hepatic mucinous cystic neoplasm were all female and ranged in age from 21 to 67 years, which was significantly younger than that in the patients with biliary intraductal papillary neoplasm. Eighteen mucinous cystic neoplasms $(76 \%)$ were located in the left lobe, with $13(54 \%)$ in segment IV. Mucinous cystic neoplasms were significantly larger than intraductal papillary neoplasms (median diameter: $110 \mathrm{vs} 50 \mathrm{~mm}, P=\mathbf{0 . 0 0 8}$ ). In contrast to intraductal papillary neoplasms that were all histologically malignant, 26 mucinous cystic neoplasms $(90 \%)$ were adenomas, $2(7 \%)$ were borderline malignant, and $1(3 \%)$ was a carcinoma in situ. Benign mucinous cystadenomas had the pure biliary immunophenotype, whereas gastrointestinal markers including cytokeratin 20 and mucin core proteins 2, 5AC, and 6 were more frequently expressed in borderline or malignant mucinous cystic neoplasms and biliary intraductal papillary neoplasms. There was no mortality in the patients with mucinous cystic neoplasm, whereas one patient with intraductal papillary neoplasm died of cancer. In conclusion, hepatic mucinous cystic neoplasms and biliary intraductal papillary neoplasms have different clinicopathological characteristics as evidenced by differences in the age and gender of patients, macroscopic appearance, immunophenotypes, and grades of malignancy.

Modern Pathology (2011) 24, 1079-1089; doi:10.1038/modpathol.2011.71; published online 22 April 2011
\end{abstract}

Keywords: cyst; cholangiocarcinoma; dysplasia; intestinal metaplasia; liver

Mucinous cystic neoplasms of the hepatobiliary system, also called biliary cystic neoplasms, are

Correspondence: Dr Y Zen, MD, PhD, FRCPath, Institute of Liver Studies, King's College Hospital, Denmark Hill, London SE5 9RS, UK.

E-mail: yoh.zen@kcl.ac.uk

*These authors contributed equally to this study.

Received 13 December 2010; revised 6 March 2011; accepted 6

March 2011; published online 22 April 2011 rare tumours usually developing within the liver. ${ }^{1}$ Clinicopathological characteristics of hepatic mucinous cystic neoplasm have not been elucidated because pathological diagnostic criteria were not clear. ${ }^{1}$ The most recent WHO classification defined the hepatic mucinous cystic neoplasms as a cyst-forming epithelial neoplasm, usually showing no communication with the bile ducts, composed of cuboidal to columnar, variably mucin-producing epithelium, and associated with ovarian-type 
subepithelial stroma. ${ }^{2}$ Mucinous cystic neoplasms need to be distinguished from other cystic liver lesions including simple cysts and cystic hamartomas. ${ }^{3}$ Recently, a unique biliary tumour named intraductal papillary neoplasm of the bile duct has been included among biliary cystic tumours. ${ }^{4}$ Biliary papillomas, biliary papillomatosis, and some of papillary cholangiocarcinomas are included in this category. Biliary intraductal papillary neoplasm is considered as a biliary counterpart of intraductal papillary mucinous neoplasms of the pancreas based on a predominant intraductal growth, ductal dilatation, and occasional overproduction of mucin. ${ }^{4}$ A previous study revealed that cystic liver tumours with bile duct communication share characteristics with intraductal papillary neoplasms, but not mucinous cystic neoplasms. ${ }^{5}$

There had been controversy regarding the distinction between mucinous cystic neoplasms and intraductal papillary neoplasms until the presence of an ovarian-like stroma was accepted as a prerequisite for the diagnosis of mucinous cystic neoplasms and the distinct entity of biliary intraductal papillary neoplasms was proposed. Most studies to date have likely examined both types of cystic tumours under a single tumour entity. ${ }^{6-8}$ Similar confusion regarding pancreatic lesions existed several decades ago. ${ }^{9}$ However, two distinct entities, pancreatic mucinous cystic neoplasms and intraductal papillary mucinous neoplasms, are now widely accepted. ${ }^{10}$

In this study, the clinicopathological characteristics of hepatic mucinous cystic neoplasms are compared with those of biliary intraductal papillary neoplasms.

\section{Patients and methods}

\section{Pathological Material}

A total of 29 surgical cases of hepatic mucinous cystic neoplasm were retrieved from the histopathology files of the Institute of Liver Studies at King's College Hospital $(n=14)$, University of Verona $(n=12)$, and Kanazawa University Hospital $(n=3)$, during the period 1991-2010. Twelve cases of cystic-type intraductal papillary neoplasm of the bile duct were also retrieved from the histopathology files of King's College Hospital, Kanazawa University Hospital, and the consultation files of one of the authors (YZ). Four of the intraductal papillary neoplasms were used in a previous study. ${ }^{5}$ Five surgical specimens with simple biliary cysts and 10 liver specimens with normal bile ducts resected for metastatic colorectal cancer were used as controls for immunohistochemistry.

The diagnosis of mucinous cystic neoplasms was based on the presence of an ovarian-like stroma in the cyst wall. Cystic-type intraductal papillary neoplasm was diagnosed on the basis of intraductal non-invasive high papillary proliferation with intraepithelial extension as described in previous studies. $^{5,11}$ All cases of intraductal papillary neoplasm showed a predominant cystic appearance on imaging. No patients had a history of chronic cholangiopathy such as intrahepatic stones or primary sclerosing cholangitis.

\section{Radiological or Macroscopic Examination}

Radiological or macroscopic features were reviewed, in particular the location (intrahepatic or hilar area; caudate lobe, left lateral segment, left medial segment (segment IV), or right lobe) and shape (unilocular, multilocular, or multicystic) of the lesion. Multilocular cysts were defined as a single cyst with multiple spaces divided by septa or showing a cyst-in-cyst appearance, the cyst outline remaining smooth. The definition of multicystic lesions was an accumulation of multiple cysts with an indented outline producing a grape-like appearance. Representative images and schema are shown in Figure 1. The presence or absence of papillary mural nodules was also recorded.

\section{Pathological Examination}

The pathological features assessed included histological grade of malignancy, tumour cell morphology, presence or absence of ovarian-like stroma, and extension into adjacent bile ducts. Histological grading was based on the basis of the highest degree of cytoarchitectural dysplasia with low-grade (adenoma), intermediate-grade (borderline malignancy), and high-grade (carcinoma in situ). ${ }^{2,12,13}$ The presence or absence of an associated invasive cancer was also recorded.

\section{Immunohistochemistry}

We examined cell phenotypes using nine proteins: cytokeratin (CK) 7, CK20, mucin core protein (MUC) 1, MUC2, MUC5AC, and MUC6 for biliary epithelium, and oestrogen receptor, progesterone receptor (PgR), and inhibin $\alpha$ for stromal cells. One representative section selected from each case was used for immunostaining. Immunostaining of the nine proteins was carried out using the EnVision + system (Dako Cytomation, Glostrup, Denmark). The deparaffinized sections were microwaved in EDTA buffer, $\mathrm{pH}$ 9.0, for $5 \mathrm{~min}$ twice at a 2-min interval. After the blocking of endogenous peroxidase by REAL Peroxidase-Blocking Solution (Dako Cytomation), the deparaffinized sections were incubated for $1 \mathrm{~h}$ at room temperature with primary monoclonal antibodies: anti-CK7 (clone OV-TL 12/30; 1:200; Dako Cytomation), anti-CK20 (clone Ks20.8; 1:100; Dako Cytomation), anti-MUC1 (clone DF3; 1:50; Abcam, Cambridge, UK), anti-MUC2 (clone Ccp58; 1:100; Novocastra Laboratories, Newcastle, UK), 
Unilocular
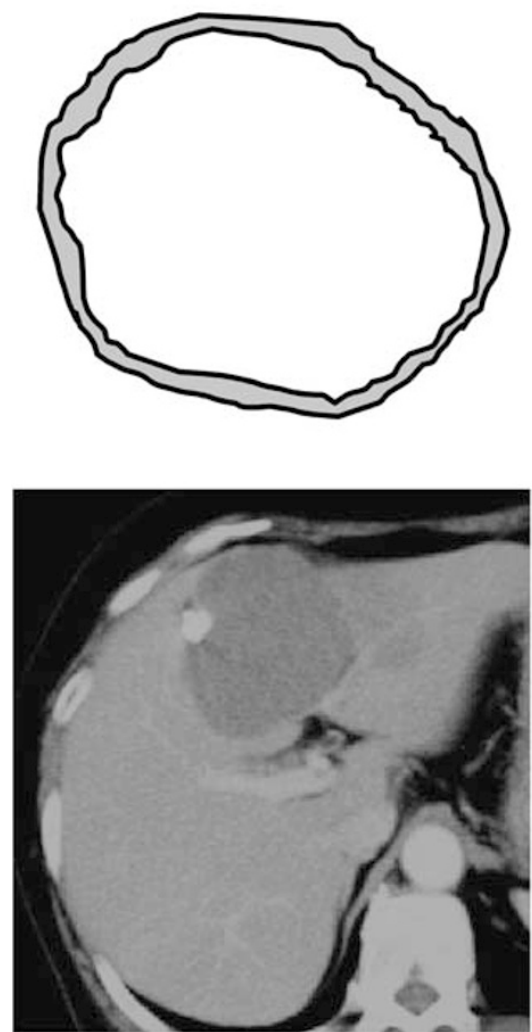

Miltilocular

(With septation or cyst-incyst appearance)
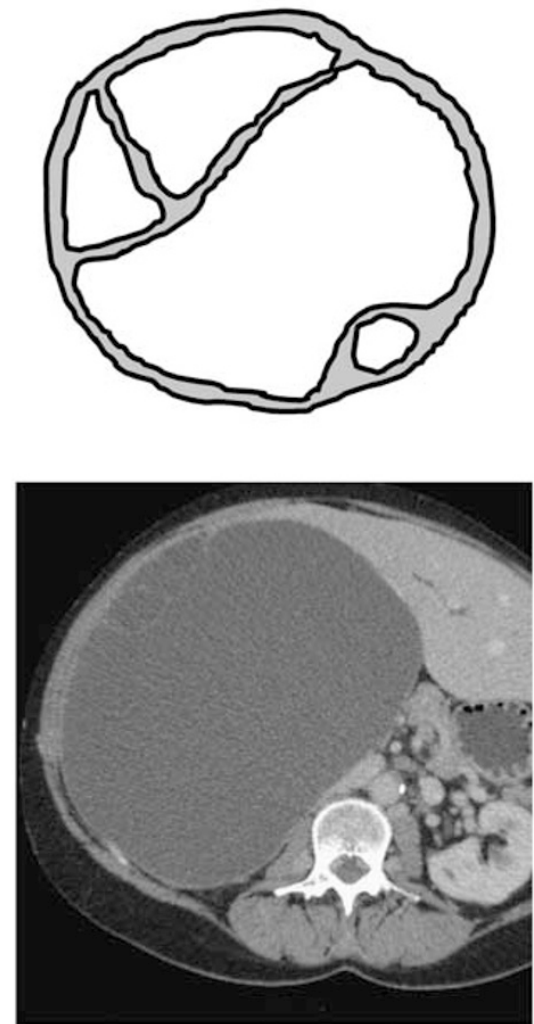

Milticystic

(Grape-like appearance)
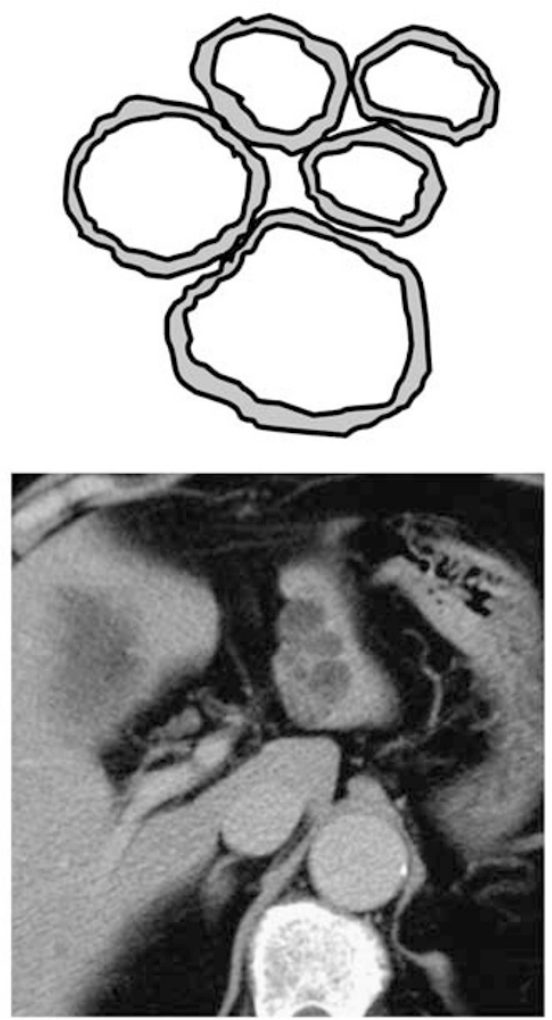

Figure 1 Radiological/macroscopic appearance of cystic tumours.

anti-MUC5AC (clone CLH2; 1:100; Novocastra Laboratories), anti-MUC6 (clone CLH5; 1:100; Novocastra Laboratories), anti-ER (clone 1D5; 1:100; Dako Cytomation), anti-PgR (clone 16; 1:40; Novocastra Laboratories), and anti-inhibin $\alpha$ (clone R1; 1:50; Dako Cytomation). The sections were then incubated at room temperature for $1 \mathrm{~h}$ with goat antimouse immunoglobulins conjugated to a peroxidase-labelled dextran polymer (EnVision +; Dako Cytomation). The reaction products were developed by immersing the section in a $3,3^{\prime}$-diaminobenzidine tetrahydrochloride solution. Nuclei were lightly counterstained with hematoxylin. The expression was evaluated semiquantitatively according to the percentage of positive epithelial or mesenchymal cells in an individual lesion: 0 (negative); $1+$ (focal), 1-10\%; $2+$ (moderate), 11-50\%; and $3+$ (marked), more than 50\%. Cases with moderate or marked expression were considered positive.

\section{Statistical Analysis}

Statistical analyses were performed using the $\chi^{2}$ or Mann-Whitney $U$-test for two groups or Tukey's test
Table 1 Gender and age of patients with hepatic mucinous cystic neoplasm or biliary intraductal papillary neoplasm

\begin{tabular}{lccr}
\hline & $\begin{array}{c}\text { Mucinous cystic } \\
\text { neoplasm } \\
(\mathrm{n}=29)\end{array}$ & $\begin{array}{c}\text { Intraductal } \\
\text { papillary } \\
\text { neoplasm } \\
(\mathrm{n}=12)\end{array}$ & P-value \\
\hline Gender (M/F) & $0 / 29$ & $6 / 6$ & $<\mathbf{0 . 0 0 1}$ \\
Age (median, range) & $45(21-69)$ & $62(43-77)$ & $\mathbf{0 . 0 0 6}$ \\
Age, $<50$ years & $16(55 \%)$ & $1(8 \%)$ & $\mathbf{0 . 0 1 6}$ \\
\hline
\end{tabular}

Bold values indicate significant difference.

for more than two groups. A probability of $P<0.05$ was considered statistically significant.

\section{Results}

\section{Clinical Features}

All patients with mucinous cystic neoplasm were female, ranging in age from 21 to 69. They were characterized by a higher ratio of female patients and younger age compared to the patients with intraductal papillary neoplasm (Table 1). Sixteen of 
29 patients (55\%) with mucinous cystic neoplasm were under 50 years, whereas 11 of 12 patients (92\%) with intraductal papillary neoplasm were over 50 years. The three patients with borderline or malignant mucinous cystic neoplasm were older than the 26 patients with benign mucinous cystadenoma (median age, 60 vs $44, P=0.049$ ).

\section{Radiological or Macroscopic Findings}

Radiological or macroscopic findings were reviewed for 26 patients with mucinous cystic neoplasm and 10 patients with intraductal papillary neoplasm. There were no available records for five earlier cases of mucinous cystic neoplasm $(n=3)$ and intraductal papillary neoplasm $(n=2)$ and data were available only after a partial cystectomy for one case of mucinous cystic neoplasm. Mucinous cystic neoplasms were larger than intraductal papillary neoplasms $(P=0.008)$. The left lobe was prevalent for both tumours, with $54 \%$ of mucinous cystic neoplasms located in the left medial segment (segment IV) (Table 2). In terms of the shape of the lesion, 21 of 26 (81\%) mucinous cystic neoplasms showed multilocular cysts with septation or a cyst-in-cyst appearance. In contrast, 8 of 10 $(80 \%)$ intraductal papillary neoplasms were multicystic with a grape-like appearance. The partially excised mucinous cystic neoplasm showed a multicystic appearance. Papillary mural nodules were noted in all intraductal papillary neoplasms $(100 \%)$, but in only one mucinous cystic neoplasm $(4 \%)$, the one with malignant features $(P<0.001)$.
The sensitivity and specificity of using the appearance of multilocular cysts for the diagnosis of mucinous cystic neoplasm were $81 \%$ and $95 \%$, respectively. A multicystic appearance is highly sensitive $(80 \%)$ and specific $(80 \%)$ for the diagnosis of intraductal papillary neoplasm, a multicystic appearance with mural nodules showing $100 \%$ specificity for intraductal papillary neoplasm.

\section{Pathological Features}

Mucinous cystic neoplasms

All mucinous cystic neoplasms had a single layered epithelium supported by fibrous connective tissue. Twenty-six cases $(90 \%)$ were adenomas consisting of minimally atypical biliary-type epithelium with occasional mucin-containing cells (Figures 2a and b). In two cases $(7 \%)$, there were atypical foci showing enlarged nuclei, nuclear stratification, and an increased nuclear/cytoplasmic ratio, but no cytological atypia of a carcinoma, and the tumours were graded as borderline malignant (Figures 2c and d). These atypical foci were histologically flat or micropapillary, and found incidentally by microscopic examination. The remaining case $(3 \%)$ was of carcinoma in situ with a marked papillary proliferation of atypical epithelium forming a complex papillotubular glandular architecture, associated with increased cellularity, nuclear pleomorphism, and occasional mitotic figures (Figure 3). Benign or borderline components were seen in adjacent flat areas.

Table 2 Radiological/macroscopic features of hepatic mucinous cystic neoplasms and biliary intraductal papillary neoplasms

\begin{tabular}{lcc}
\hline & $\begin{array}{c}\text { Mucinous cystic } \\
\text { neoplasm }(\mathrm{n}=26)^{\mathrm{a}}\end{array}$ & $\begin{array}{c}\text { Intraductal papillary } \\
\text { neoplasm (n=10) }\end{array}$ \\
\hline Size (median, range) & $110 \mathrm{~mm}(25-250)$ & $50 \mathrm{~mm}(25-140)$ \\
Location & $24(92 \%)$ & $9(90 \%)$ \\
Intrahepatic & $2(8 \%)$ & $1(10 \%)$ \\
Hilar & & $\mathbf{0 . 0 0 8}$ \\
Lobe or segment & $1(4 \%)$ & $1(10 \%)$ \\
Caudate lobe & $5(21 \%)$ & $3(30 \%)$ \\
Left lateral segment & $13(54 \%)$ & $3(30 \%)$ \\
Left medial segment & $5(21 \%)$ & $3(30 \%)$ \\
Right lobe & & $1(10 \%)$ \\
Shape & $3(11 \%)$ & $1(10 \%)$ \\
Unilocular & $21(81 \%)$ & $8(80 \%)$ \\
Multilocular & $2(8 \%)$ & $10(100 \%)$ \\
Multicystic & & 0.777 \\
Papillary mural nodule & $1(4 \%)^{\mathrm{c}}$ & $<\mathbf{0 . 0 0 1}$ \\
Presence & $25(96 \%)$ & $<\mathbf{0 . 0 0 1}$ \\
Absence & & \\
\hline
\end{tabular}

\footnotetext{
${ }^{\mathrm{a}}$ No record available in five old cases (three mucinous cystic neoplasms and two intraductal papillary neoplasms).

${ }^{\mathrm{b}}$ Two mucinous cystic neoplasms in hilar tissue could not be further located.

${ }^{\mathrm{C}}$ Carcinoma in situ case.

Bold values indicate significant difference.
} 
a
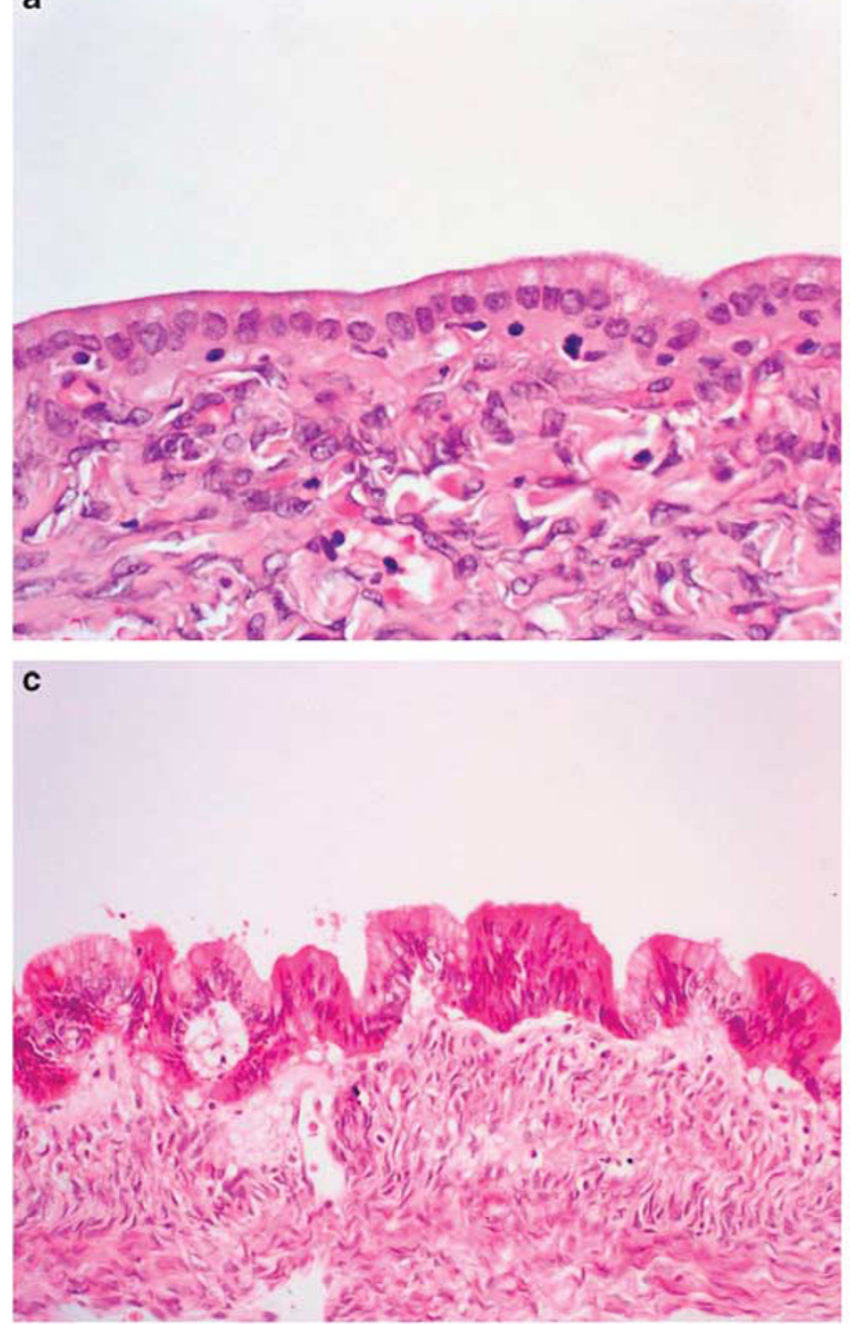

b

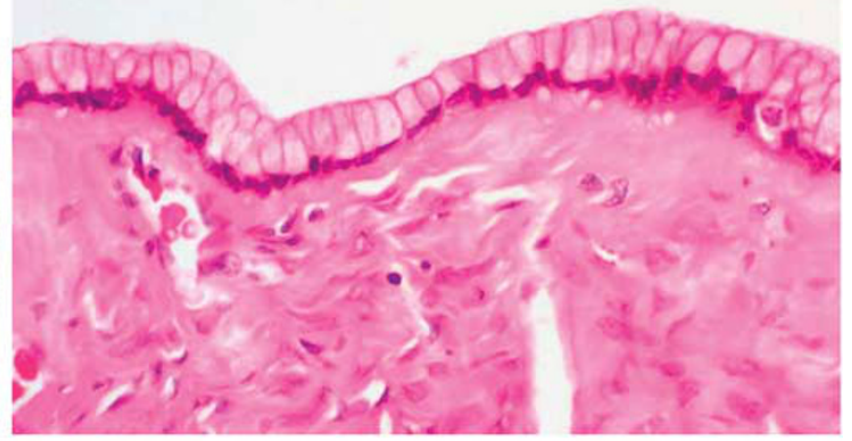

d

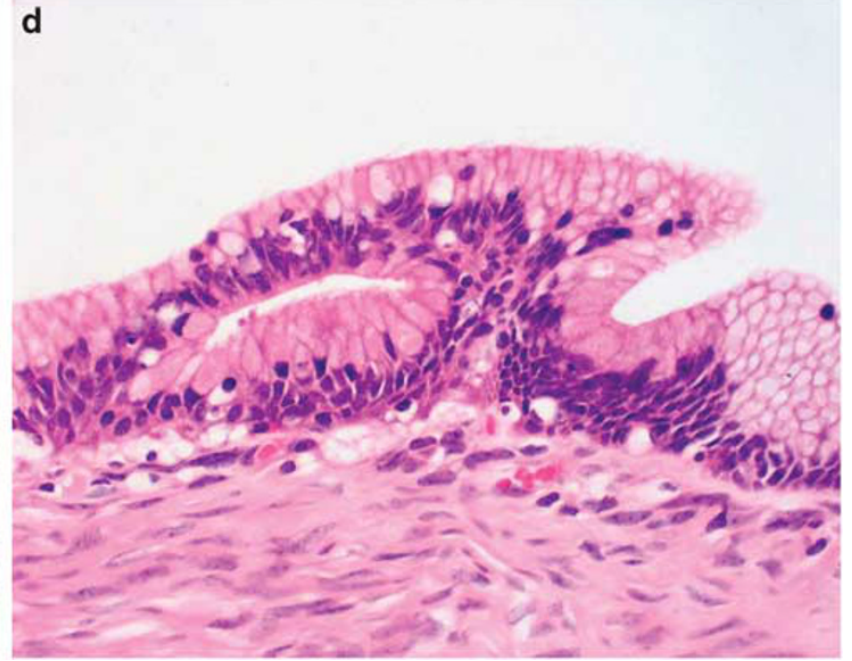

Figure 2 Histopathology of hepatic mucinous cystic neoplasms. Benign mucinous cystadenomas show a single layered biliary-type epithelium (a) with occasional foci of mucin-containing cells (b). Borderline tumours exhibit cellular atypia such as nuclear enlargement and stratification (c, d). Original magnification: a, b, d, $\times 400 ; \mathbf{c}, \times 200$.

An ovarian-like stroma consisting of cellular spindle cells was easily and relatively diffusely identified in all cases. In the case of carcinoma in situ, the stroma was also noted in papillary areas (Figure 3). Haemosiderin deposition was noted in 13 cases, cholesterol clefts in nine cases, and small foci of calcification in five cases. Features suggestive of ductal communication such as the presence of peribiliary glands in the cyst wall or the presence of hepatic parenchyma entrapped in the interlocular septa were not identified.

Comparison with intraductal papillary neoplasms All intraductal papillary neoplasms showed extensive papillary proliferation of atypical epithelium within the cystic space (Figures 4a and b). Ten cases of intraductal papillary neoplasms (83\%) were graded as carcinoma in situ, and the remaining two case had foci of invasion (microinvasive mucinous carcinoma in one and invasive tubular adenocarcinoma in the other). In all intraductal papillary neoplasms, bile duct communication was evidenced by the presence of intraepithelial neoplasms within adjacent bile ducts, or the presence of peribiliary glands in the cyst wall (Figures 4c and d). No ovarian-like stroma was found in any cases of intraductal papillary neoplasm (Table 3).

\section{Immunohistochemistry}

Normal bile ducts

Normal bile ducts had the immunophenotype $\mathrm{CK}^{+}{ }^{+}$/ CK20-/MUC1-/MUC2-/MUC5AC ${ }^{-}$. MUC6 was expressed in peribiliary glands in two cases.

\section{Simple cysts}

The surface epithelium of simple cysts showed the immunophenotype $\mathrm{CK} 7^{+} / \mathrm{CK} 20^{-} / \mathrm{MUC}^{-} / \mathrm{MUC}^{-}{ }^{-}$ 

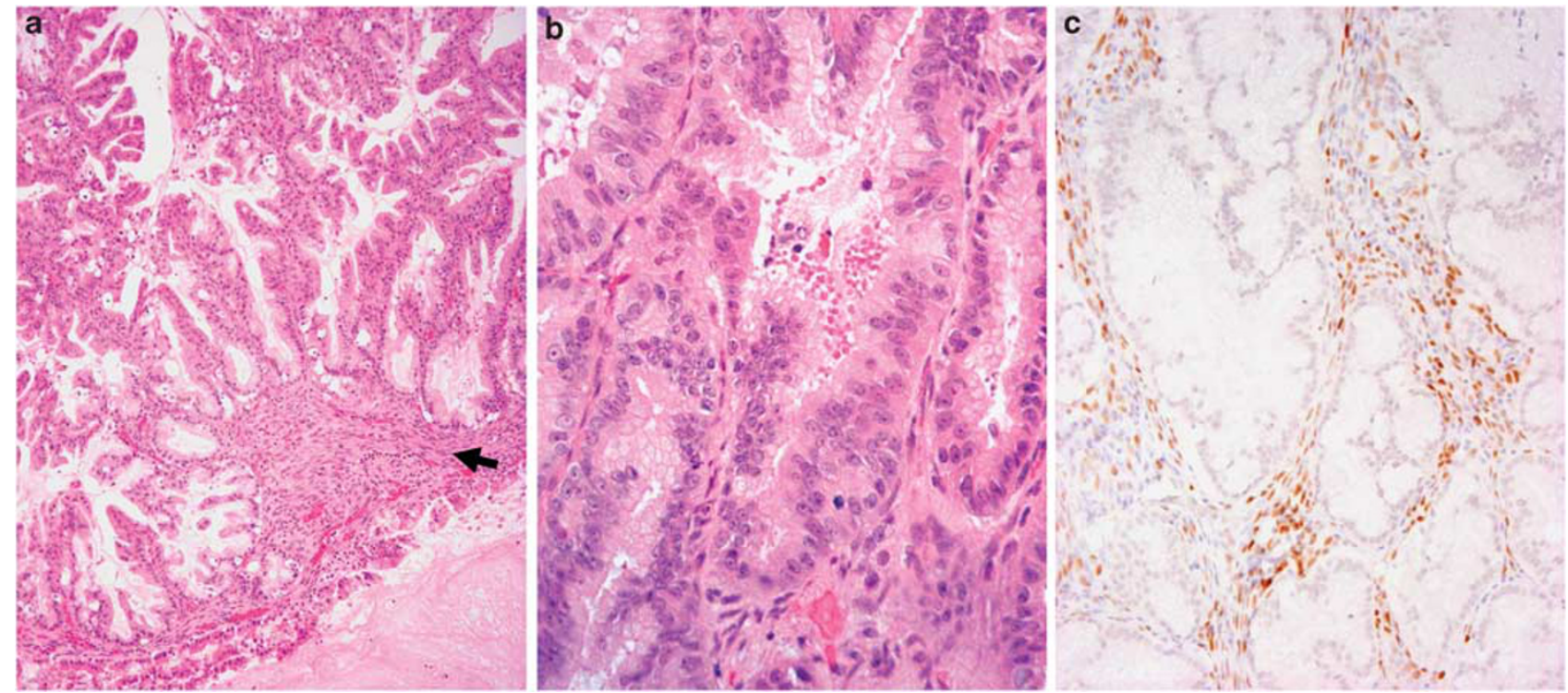

Figure 3 A carcinoma in situ case of hepatic mucinous cystic neoplasm. (a) There is papillary proliferation of atypical epithelium with fibrovascular cores. Ovarian-like stroma is noted (arrow). (b) Nuclear enlargement with occasional foci of loss of polarity is seen. (c) Immunostaining for the progesterone receptor reveals a stroma positive for progesterone receptor in fibrovascular cores of the papillary lesion. Original magnification: a, $\times 100 ; \mathbf{b}, \mathbf{c}, \times 400$.

MUC6 $^{-}$. MUC5AC expression was observed in one case $(20 \%)$.

\section{Mucinous cystic neoplasms}

All benign mucinous cystadenomas $(n=26)$ showed the biliary immunophenotype $\mathrm{CK}^{+} / \mathrm{CK}^{-}{ }^{-} /$ MUC2 $^{-} / \mathrm{MUC5}^{-} \mathrm{AC}^{-} / \mathrm{MUC6}^{-}$(Figure 5). The expression of MUC2 and MUC5AC was focally observed in 11 and one adenoma, respectively (less than $2 \%$ of tumour cells). Gastrointestinal markers such as CK20, MUC2, MUC5AC, and MUC6 were more frequently expressed in borderline or malignant tumours than benign mucinous cystadenomas (all, $P<0.001$ ) (Table 4 and Figures 5). MUC2 and MUC5AC were expressed in all borderline and malignant cases. MUC2 positivity was restricted to goblet cells. Moderate to marked expression of MUC1 was observed only in the carcinoma in situ case (Figure 5). Regarding the ovarian-like stroma, ER, PgR, and inhibin $\alpha$ were expressed in $19(67 \%), 27(93 \%)$, and $6(20 \%)$ cases, respectively (Figure 3c).

\section{Intraductal papillary neoplasms}

The expression of CK7 was decreased in two cases: a very focal expression in one case and no expression in the other. Intestinal markers (CK20 and MUC2) were expressed in $2(17 \%)$ and $5(42 \%)$ cases, respectively. Gastric markers (MUC5AC and MUC6) were expressed in most cases. Moderate to marked expression of MUC1 was observed in $6(50 \%)$ cases, including invasive cases. No expression of ER, PgR, and inhibin $\alpha$ was seen in any cases.
Comparison between mucinous cystic neoplasms and intraductal papillary neoplasms

The expression of CK7 was less common in intraductal papillary neoplasms, whereas the expression of MUC1, MUC2, MUC5AC, and MUC6 was significantly more common in intraductal papillary neoplasms (Table 4). The expression of gastrointestinal markers was similarly common in borderline or malignant mucinous cystic neoplasms and intraductal papillary neoplasms. In contrast, benign mucinous cystadenomas had a pure biliary immunophenotype. Moderate to marked expression of MUC1 was only observed in malignant cases in both types of tumours.

\section{Recurrence}

Follow-up data were reviewed for 24 patients with mucinous cystic neoplasm and 12 patients with intraductal papillary neoplasm. No records were available for five earlier cases of mucinous cystic neoplasm. All the patients with mucinous cystic neoplasm were treated surgically, and none died of this tumour (follow-up period, 1-132 months, median 47 months). Eighteen (75\%) patients were treated by single surgical resection. Two (8\%) patients, including the one with the carcinoma in situ, first underwent a partial cystectomy with fenestration in referring hospitals before undergoing a complete excision. One additional patient (4\%) underwent a left hepatectomy for a large tumour predominantly in segment IV. Parts of the tumour remained in the right lobe, but have not changed in 

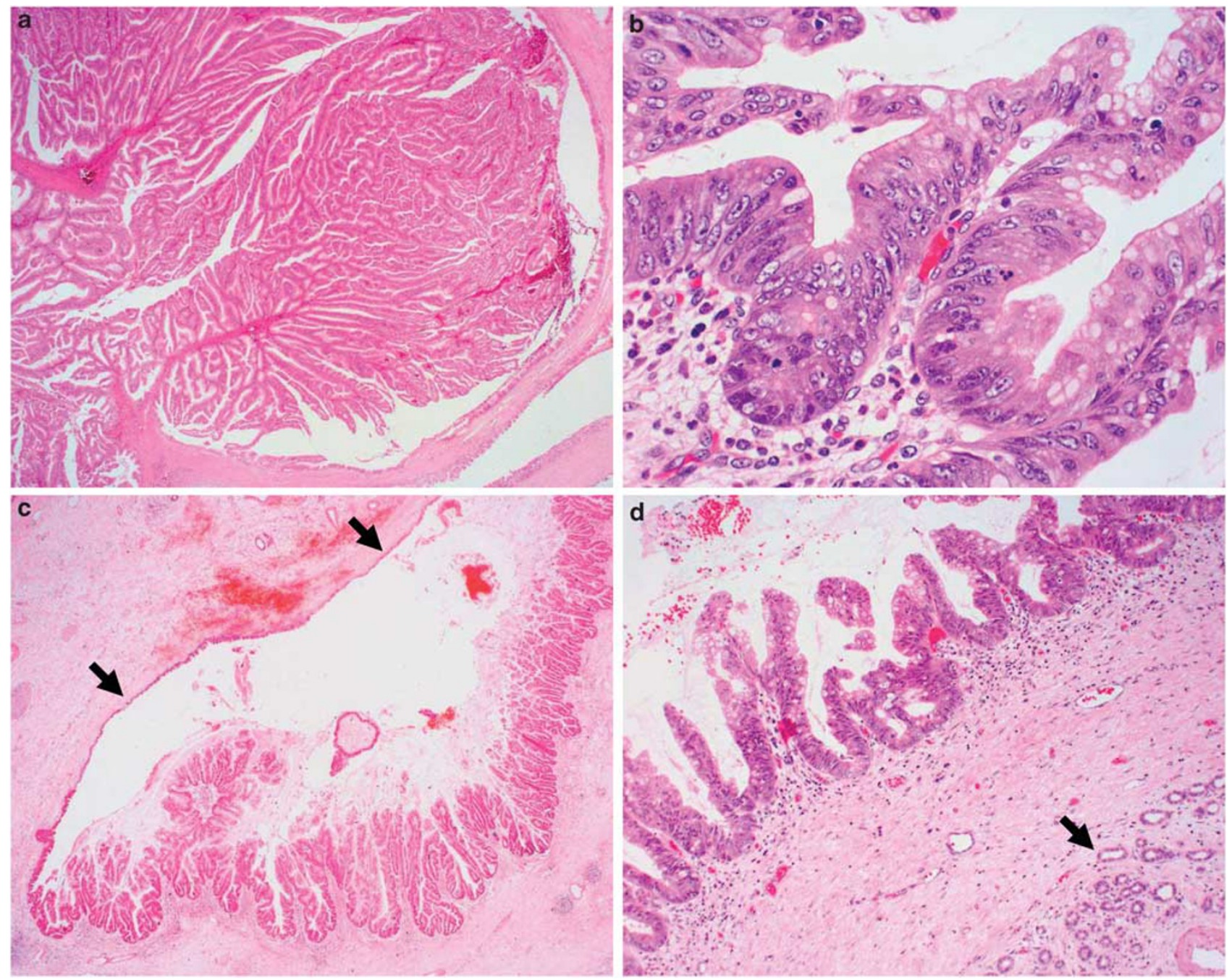

Figure 4 Histopathology of biliary intraductal papillary neoplasms. (a) There is a papillary tumour in the cystic space. (b) The tumour consists of large atypical cells with occasional intracytoplasmic mucin. (c) An intraductal extension of the tumour is noted in a large bile duct. Arrows indicate non-neoplastic biliary epithelium. (d) Peribiliary glands are seen in the cyst wall (arrow). Original magnification: a, c, $\times 20 ; \mathbf{b}, \times 400 ; \mathbf{d}, \times 100$.

Table 3 Pathological features of hepatic mucinous cystic neoplasms and biliary intraductal papillary neoplasms

\begin{tabular}{lcc}
\hline & $\begin{array}{c}\text { Mucinous cystic } \\
\text { neoplasm }(\mathrm{n}=29)\end{array}$ & $\begin{array}{c}\text { Intraductal papillary } \\
\text { neoplasm (n=12) }\end{array}$ \\
\hline $\begin{array}{l}\text { Grading } \\
\text { Adenoma }\end{array}$ & $26(90 \%)$ & 0 \\
$\quad$ Borderline & $2(7 \%)$ & 0 \\
Malignancy & $1(3 \%)$ & $12(100 \%)$ \\
Ductal communication & & $12(100 \%)$ \\
$\quad \begin{array}{l}\text { Presence } \\
\text { Absence }\end{array}$ & 0 & 0 \\
Ovarian-like stroma & $29(100 \%)$ & \\
$\quad \begin{array}{l}\text { Presence } \\
\text { Absence }\end{array}$ & $29(100 \%)$ & 0 \\
\hline
\end{tabular}

Bold values indicate significant difference.

appearance or size over a follow-up period of 6 years and 9 month. The remaining three $(13 \%)$ patients (all benign cases) were radiologically found to have a recurrent mucinous cystic neoplasm (5 months, 7 years, and 8 years and 7 months after the first operation). Interestingly, one recurrent mucinous 

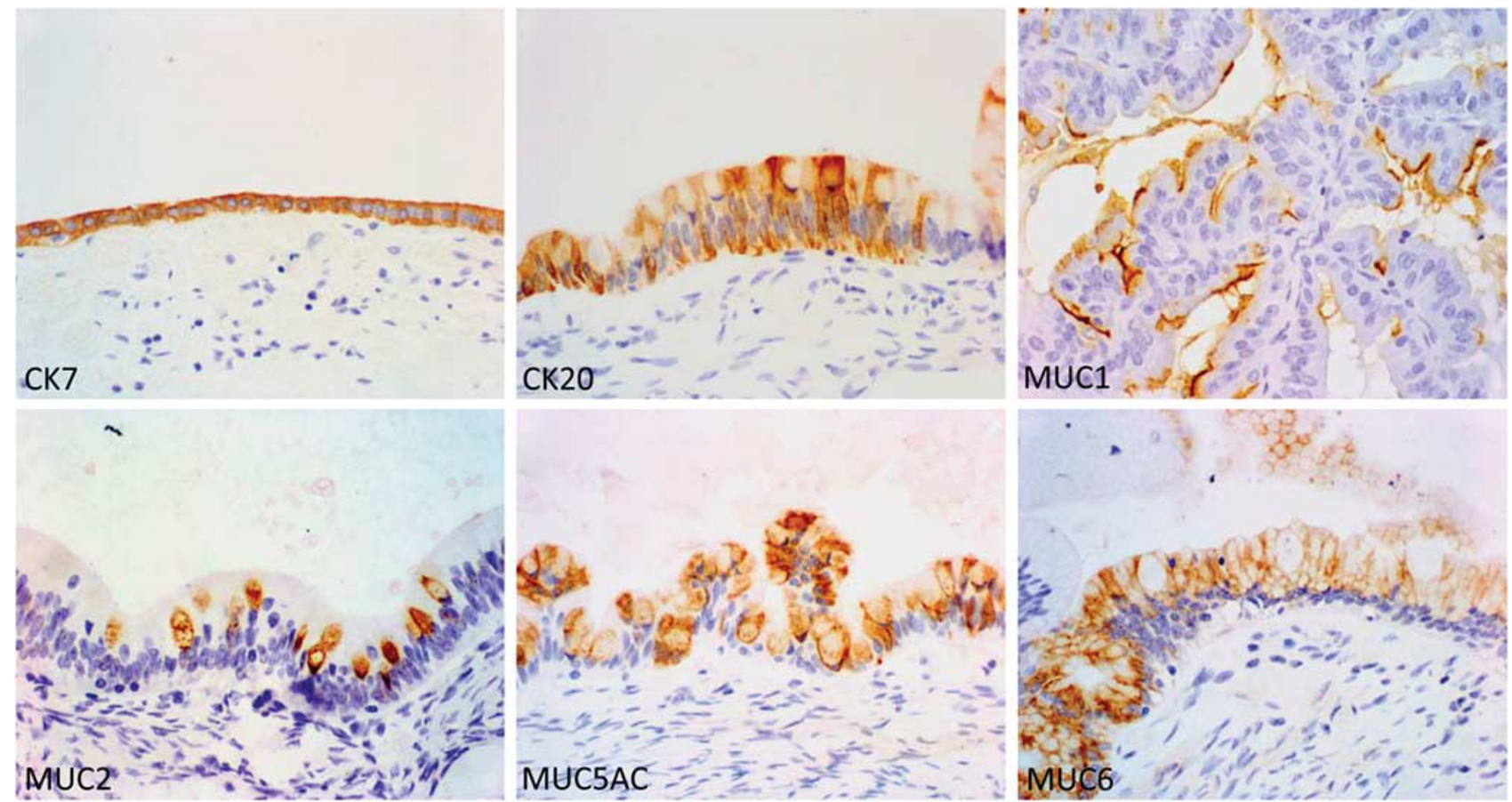

Figure 5 Immunohistochemistry in hepatic mucinous cystic neoplasms. Cytokeratin (CK) 7 expression is observed in a benign cystadenoma. Expression of CK20, mucin core protein (MUC)2, MUC5AC, and MUC6 is noted in borderline tumours. MUC1 is expressed on apical membrane of a malignant mucinous cystic neoplasm. Original magnifications: all, $\times 400$.

Table 4 Results of immunohistochemistry

\begin{tabular}{|c|c|c|c|c|c|c|c|c|}
\hline & \multirow{2}{*}{$\begin{array}{c}\text { Normal bile } \\
\text { duct } \\
(\mathrm{n}=10)\end{array}$} & \multirow{2}{*}{$\begin{array}{l}\text { Simple } \\
\text { cyst } \\
(\mathrm{n}=5)\end{array}$} & \multirow{2}{*}{$\begin{array}{c}\text { Mucinous } \\
\text { cystic neoplasm } \\
(\mathrm{n}=29)\end{array}$} & \multirow{2}{*}{$\begin{array}{l}\text { Intraductal } \\
\text { papillary } \\
\text { neoplasm } \\
(\mathrm{n}=12)\end{array}$} & \multirow[t]{2}{*}{ P-value } & \multicolumn{2}{|c|}{ Mucinous cystic neoplasm } & \multirow[t]{2}{*}{$\mathrm{P}$-value ${ }^{\mathrm{b}}$} \\
\hline & & & & & & $\begin{array}{l}\text { Benign } \\
(\mathrm{n}=26)\end{array}$ & $\begin{array}{l}\text { Borderline to CIS } \\
\quad(\mathrm{n}=3)\end{array}$ & \\
\hline CK7 & $10(100 \%)$ & $10(100 \%)$ & $29(100 \%)$ & $10(83 \%)$ & 0.276 & $26(100 \%)$ & $3(100 \%)$ & Identical \\
\hline CK20 & 0 & 0 & $2(7 \%)$ & $2(17 \%)$ & 0.703 & 0 & $2(67 \%)$ & 0.002 \\
\hline MUC1 & 0 & 0 & $1(3 \%)$ & $6(50 \%)$ & 0.002 & 0 & $1(33 \%)$ & 0.185 \\
\hline MUC2 & 0 & 0 & $2(7 \%)$ & $5(42 \%)$ & 0.025 & 0 & $2(67 \%)$ & 0.002 \\
\hline MUC5AC & 0 & $1(20 \%)$ & $3(10 \%)$ & $12(100 \%)$ & $<0.001$ & 0 & $3(100 \%)$ & $<0.001$ \\
\hline MUC6 & $2(20 \%)^{\mathrm{c}}$ & 0 & $2(7 \%)$ & $10(83 \%)$ & $<0.001$ & 0 & $2(67 \%)$ & 0.002 \\
\hline
\end{tabular}

CIS, carcinoma in situ.

${ }^{\mathrm{a} B e t w e e n ~ M C N ~ a n d ~ I P N B . ~}$

${ }^{\mathrm{b}}$ Between benign and borderline to CIS.

${ }^{\mathrm{c}}$ Expression in peribiliary glands.

Bold values indicate significant difference.

cystic neoplasm had increased in size at the time of pregnancy. All resected recurrent tumours were cystadenoma without malignant transformation.

All patients with intraductal papillary neoplasm except one were treated by complete surgical resection. No recurrence has been observed during a median follow-up period of 44 months. A complete resection was impossible in the remaining patient with a widely invasive tumour. This patient died of Budd-Chiari syndrome due to carcinoma invasion into vena cava.

\section{Discussion}

The clinicopathological findings characteristic of hepatic mucinous cystic neoplasms can be summarized as follows: (1) patients are female and range widely in age; (2) multilocular cysts with septation or a cyst-in-cyst appearance are distinctive; (3) 90\% of cases are histologically benign; (4) a gastrointestinal immunophenotype seems important to the histological progression; and (5) although local recurrence rarely occurs, at times years after surgery, 
the prognosis is excellent. There has been controversy regarding the distinction between hepatic mucinous cystic neoplasms and biliary intraductal papillary neoplasms, but this study reveals clinicopathological differences that are sufficient to support that these tumours are two distinct entities.

In the largest study of pancreatic mucinous cystic neoplasm to date, 155 of 163 (95\%) patients were female, and ranged in age from 16 to $82 .{ }^{14}$ These demographic data are similar to those for hepatic mucinous cystic neoplasm, except for rare cases of pancreatic cystadenoma occurring in men. Almost all pancreatic mucinous cystic neoplasms (97\%) were located on the left side (the body-tail) of the pancreas. ${ }^{14}$ Hepatic mucinous cystic neoplasms were similarly common on the left side $(75 \%)$. The postoperative survival rate was excellent for both hepatic and pancreatic mucinous cystic neoplasms, with no mortality recorded in both studies.

However, there are several pathological differences between hepatic and pancreatic mucinous cystic neoplasms. The proportion of malignant tumours was higher in pancreatic cases. Of 163 patients with pancreatic mucinous cystic neoplasms, $118(72 \%)$ were adenomas, 17 borderline neoplasms (10.5\%), 9 carcinomas in situ $(5.5 \%)$, and 19 were invasive carcinomas $(12 \%) .{ }^{14}$ Lüttges et al ${ }^{15}$ reported that MUC2 expression in pancreatic mucinous cystic neoplasm was confined to goblet cells, which were numerous in borderline or malignant cases, but rare in adenomas. This is in line with our results in hepatic mucinous cystic neoplasms. In contrast, MUC5AC and CK20 were expressed in the majority of pancreatic mucinous cystic neoplasms irrespective of the grade of dysplasia, ${ }^{15,16}$ which differs markedly from the immunophenotype found in our study.

Of interest, only one (3\%) hepatic mucinous cystic neoplasm was malignant, a rate quite low compared with previous reports. Studies not using the ovarian-like stroma as a diagnostic criterion found the ratio of malignant cases of biliary cystic tumours to be $21-26 \% .^{6,7}$ Ovarian-like stroma was less commonly observed in the malignant cases in these studies. ${ }^{6,7}$ Presumably, cases of cystic-type intraductal papillary neoplasm were included in the malignant groups in these studies, given that almost all cases of biliary intraductal papillary neoplasm were at least carcinoma in situ. However, even in studies restricted to cystic tumours with ovarianlike stroma, $17-19 \%$ of tumours were malignant. ${ }^{17,18}$ One possible explanation for this discrepancy is that owing to recent advances in imaging modalities, patients in this study were diagnosed at a younger age; patients with malignant hepatic and pancreatic mucinous cystic neoplasms were older than those with benign cystadenomas. ${ }^{14,18}$ This may stress the importance to treat patients with hepatic mucinous cystic neoplasm at a young age to reduce the risk of malignant transformation.
This study suggested that hepatic mucinous cystic neoplasms and biliary intraductal papillary neoplasms can differ in radiological or macroscopic appearance. Lim et $a l^{19}$ also reported that intraductal papillary neoplasms more commonly show peripheral bile duct dilatation than mucinous cystic neoplasms. However, the clinical diagnosis of biliary cystic lesions remains challenging, due to other hamartomatous and developmental cystic lesions with or without cholangiocarcinoma, which may mimic mucinous cystic neoplasms. ${ }^{20}$ In addition, about $10 \%$ of hepatic mucinous cystic neoplasms manifest as unilocular cystic lesions, which are difficult to differentiate from solitary simple cysts. Interestingly, two hepatic mucinous cystadenoma in this study appeared as unilocular cyst radiologically, but small intramural cysts were identified on macroscopic examination of the resected specimen and therefore categorized as multilocular cysts in this study. Further development of radiological modalities will be needed to detect such small mural cysts.

Two major pathways have been suggested for biliary carcinogenesis. More commonly, biliary intraepithelial neoplasia (biliary dysplasia) evolve into cholangiocarcinoma usually manifesting as an infiltrative tubular adenocarcinoma. ${ }^{11,21}$ The other pathway, intraductal papillary neoplasm to invasive cancer, is characterized by a potential progression to both mucinous carcinoma and papillotubular carcinoma, the expression of gastrointestinal markers even in early lesions (adenomas), and a more favourable postoperative prognosis. ${ }^{11,22}$ This study suggested that mucinous cystic neoplasm may be a tumour precursor through another route characterized by the least aggressive clinical course and by expression of gastrointestinal molecules during the carcinogenetic process.

Regarding the location of biliary cystic tumours, most mucinous cystic neoplasms arise in the liver, except for rare tumours in the gallbladder or common bile duct. ${ }^{6,17}$ Biliary intraductal papillary neoplasm can arise in both extrahepatic and intrahepatic bile ducts, but most cyst-forming tumours affect hilar or intrahepatic bile ducts. ${ }^{5}$ In our experience, the incidence of hepatic mucinous cystic neoplasm is higher than that of biliary intraductal papillary neoplasm in European countries. In contrast, biliary intraductal papillary neoplasm is more commonly seen in Asian countries partly because of a higher incidence of hepatolithiasis or Clonorchiasis infection, ${ }^{11,23}$ whereas hepatic mucinous cystic neoplasm is extremely rare in Japan.

The origin of hepatic and pancreatic mucinous cystic neoplasms has not been elucidated. Mucinous cystic neoplasms may develop from endodermal immature stroma or primary yolk cells implanted during embryogenesis. ${ }^{24,25}$ The prevalence of hepatic mucinous cystic neoplasm in segment IV may support an implant origin because hamartomatous 
lesions commonly develop in segment IV. ${ }^{26,27}$ The expression of oestrogen receptor or PgR in ovarianlike stroma also supports a putative role for female hormones in the tumorigenesis. ${ }^{28}$

In conclusion, hepatic mucinous cystic neoplasms and biliary intraductal papillary neoplasms have different clinicopathological characteristics as evidenced by differences in the age and gender of patients, macroscopic appearance, immunophenotypes, and grades of malignancy. It is rational to use the presence of ovarian-like stroma to differentiate hepatic mucinous cystic neoplasms from biliary intraductal papillary neoplasms.

\section{Disclosure/conflict of interest}

The authors declare no conflict of interests.

\section{References}

1 Wittekind C, Fischer HP, Ponchon T. Bile duct cystadenoma and cystadenocarcinoma. In: Hamilton SR, Aaltonen LA (eds). World Health Organization Classification of Tumours. Pathology and Genetics of Tumours of the Digestive System. IARC Press: Lyon, 2000, pp 182-183.

2 Tsui WMS, Adsay NV, Crawford JM, et al. Mucinous cystic neoplasms of the liver. In: Bosman FT, Carneiro F, Hruban RH, Theise ND (eds). World Health Organization Classification of Tumours. Pathology and Genetics of Tumours of the Digestive System. IARC Press: Lyon, 2010, pp 236-238.

3 Seo JK, Kim SH, Lee SH, et al. Appropriate diagnosis of biliary cystic tumors: comparison with atypical hepatic simple cysts. Eur J Gastroenterol Hepatol 2010;22: 989-996.

4 Chen TC, Nakanuma Y, Zen Y, et al. Intraductal papillary neoplasia of the liver associated with hepatolithiasis. Hepatology 2001;34:651-658.

5 Zen Y, Fujii T, Itatsu K, et al. Biliary cystic tumors with bile duct communication: a cystic variant of intraductal papillary neoplasm of the bile duct. Mod Pathol 2006;19:1243-1254.

6 Devaney K, Goodman ZD, Ishak KG. Hepatobiliary cystadenoma and cystadenocarcinoma. A light microscopic and immunohistochemical study of 70 patients. Am J Surg Pathol 1994;18:1078-1091.

7 Buetow PC, Buck JL, Pantongrag-Brown L, et al. Biliary cystadenoma and cystadenocarcinoma: clinical-imaging-pathologic correlations with emphasis on the importance of ovarian stroma. Radiology 1995;196:805-810.

8 Lewin M, Mourra N, Honigman I, et al. Assessment of MRI and MRCP in diagnosis of biliary cystadenoma and cystadenocarcinoma. Eur Radiol 2006;16:407-413.

9 Warshaw AL, Compton CC, Lewandrowski K, et al. Cystic tumors of the pancreas. New clinical, radiologic, and pathologic observations in 67 patients. Ann Surg 1990;212:432-443.

10 Tanaka M, Chari S, Adsay V, et al. International consensus guidelines for management of intraductal papillary mucinous neoplasms and mucinous cystic neoplasms of the pancreas. Pancreatology 2006;6: 17-32.
11 Zen Y, Sasaki M, Fujii T, et al. Different expression patterns of mucin core proteins and cytokeratins during intrahepatic cholangiocarcinogenesis from biliary intraepithelial neoplasia and intraductal papillary neoplasm of the bile duct-an immunohistochemical study of 110 cases of hepatolithiasis. J Hepatol 2006;44:350-358.

12 Nakanuma Y, Curado MP, Franceschi S, et al. Intrahepatic cholangiocarcinoma. In: Bosman FT, Carneiro F, Hruban RH, Theise ND (eds). World Health Organization Classification of Tumours. Pathology and Genetics of Tumours of the Digestive System. IARC Press: Lyon, 2010, pp 217-224.

13 Albores-Saavedra J, Adsay NV, Crawford JM, et al. Carcinoma of the gallbladder and extrahepatic bile ducts. In: Bosman FT, Carneiro F, Hruban RH, Theise ND (eds). World Health Organization Classification of Tumours. Pathology and Genetics of Tumours of the Digestive System. IARC Press: Lyon, 2010, pp 266-273.

14 Crippa S, Salvia R, Warshaw AL, et al. Mucinous cystic neoplasm of the pancreas is not an aggressive entity: lessons from 163 resected patients. Ann Surg 2008;247:571-579.

15 Lüttges J, Feyerabend B, Buchelt $\mathrm{T}$, et al. The mucin profile of noninvasive and invasive mucinous cystic neoplasms of the pancreas. Am J Surg Pathol 2002;26:466-471.

16 Nishigami T, Onodera M, Torii I, et al. Comparison between mucinous cystic neoplasm and intraductal papillary mucinous neoplasm of the branch duct type of the pancreas with respect to expression of CD10 and cytokeratin 20. Pancreas 2009;38:558-564.

17 Wheeler DA, Edmondson HA. Cystadenoma with mesenchymal stroma (CMS) in the liver and bile ducts. A clinicopathologic study of 17 cases, 4 with malignant change. Cancer 1985;56:1434-1445.

18 Akwari OE, Tucker A, Seigler HF, et al. Hepatobiliary cystadenoma with mesenchymal stroma. Ann Surg 1990;211:18-27.

19 Lim JH, Jang KT, Rhim $\mathrm{H}$, et al. Biliary cystic intraductal papillary mucinous tumor and cystadenoma/cystadenocarcinoma: differentiation by CT. Abdom Imaging 2007;32:644-651.

20 Ryu Y, Matsui O, Zen Y, et al. Multicystic biliary hamartoma: imaging findings in four cases. Abdom Imaging 2010;35:543-547.

21 Zen Y, Adsay NV, Bardadin K, et al. Biliary intraepithelial neoplasia: an international interobserver agreement study and proposal for diagnostic criteria. Mod Pathol 2007;20:701-709.

22 Zen Y, Fujii T, Itatsu K, et al. Biliary papillary tumors share pathological features with intraductal papillary mucinous neoplasm of the pancreas. Hepatology 2006;44:1333-1343.

23 Jang KT, Hong SM, Lee KT, et al. Intraductal papillary neoplasm of the bile duct associated with Clonorchis sinensis infection. Virchows Arch 2008; 453:589-598.

24 Zamboni G, Scarpa A, Bogina G, et al. Mucinous cystic tumors of the pancreas: clinicopathological features, prognosis, and relationship to other mucinous cystic tumors. Am J Surg Pathol 1999;23: 410-422.

25 Erdogan D, Lamers WH, Offerhaus GJ, et al. Cystadenomas with ovarian stroma in liver and pancreas: an evolving concept. Dig Surg 2006;23:186-191. 
26 Kadoya M, Matsui O, Nakanuma Y, et al. Ciliated hepatic foregut cyst: radiologic features. Radiology 1990;175:475-477.

27 Zen Y, Terahata S, Miyayama S, et al. Multicystic biliary hamartoma: a hitherto undescribed lesion. Hum Pathol 2006;37:339-344.
28 Ganepola GA, Gritsman AY, Asimakopulos N, et al. Are pancreatic tumors hormone dependent?: A case report of unusual, rapidly growing pancreatic tumor during pregnancy, its possible relationship to female sex hormones, and review of the literature. Am Surg 1999;65:105-111. 